\title{
O campo não hermenêutico ou a materialidade da comunicação
}

\author{
Hans Ulrich Gumbrecht
}




\section{Introdução}

Estou contente por voltar ao Rio de Janeiro. Não apenas por conta de uma simples retórica acadêmica, senão porque as três vezes em que aqui estive representaram ocasiões para resumir determinadas etapas de minha vida intelectual e, ao mesmo tempo, o princípio de novo caminho. Portanto, sempre em momentos transitórios de meu trabalho, o que acredito poderia ser verdade uma vez mais.

Por isto mencionarei brevemente os temas dos três seminários que, como professor visitante, coordenei. Ao fazê-lo, menos que oferecer uma autobiografia intelectual, pretendo introduzir a problemática que desenvolverei.

Em 1977, em minha primeira viagem profissional ao Brasil, dispunha de todo um mês para apresentar uma teoria da comunicação literária fenomenologicamente fundada. Estava então baseado num conceito de ação, ou de ato, muito próximo ao do sociólogo Max Weber. Conceito, ao mesmo tempo, relacionado a e diverso da teoria dos atos da fala, à época muito discutida.

Baseava-me também no conceito fenomenológico de "saber social", desenvolvido pelo sociólogo alemão Alfred Schütz. Conceito próximo ao de ideologia, tal como postulado pela Crítica Ideológica, embora sem com ele confundir-se.

Em 1982, desenvolvi, na Faculdade da Cidade, um seminário fundado nestas teorias, compreendidas, porém, sob uma ótica radicalmente histórica. Para tanto, apresentei e levei adiante a hipótese de historicizar o conceito de literatura. Segundo tal hipótese, a forma especial de comunicação denominada "literatura" emergiu de um contexto histórico muito particular associado ao colapso da cosmologia medieval $c$ : à situação caótica daí originada. Nesta situação, fundou-se uma nova técnica de produção do sentido; técnica centrada no que denominamos "o sujeito". Deste modo, pode-se relacionar a emergência do conceito e da forma de comunicação designada literatura à emergência do sujeito enquanto centro desde o qual se engendra o sentido. Quero também mencionar o meu orgulho porque Luiz Costa Lima, com bastante gentileza, no primeiro volume da trilogia do Controle do imaginário, atribui a tais discussões, embora não seja verdade, a origem de seu pensamento sobre o imaginário.

Por fim, em 1988, na PUC, apresentei um seminário muito breve sobre o conceito de pós-moderno. Todavia, tentava fugir do que nos Estados Unidos diríamos

\footnotetext{
* Este texto resulta de uma conferência realizada em maio de 1992, na UERJ. De comum acordo com o autor, preservou-se o caráter de apresentaçāo oral. [Tradução João Cezar de Castro Rocha]. Originalmente publicado por Cadernos de Mestrado/ Literatura. Rio de Janeiro: UERJ-IL, n. 5, 1993.
} 
constituir "o tema da moda". Buscava parecer o menos "vanguardeiro" (trendy) possível. Para tanto, tentei descrever uma situação posterior ao fracasso do projeto histórico representado pelo que chamamos a "modernidade". Seminário baseado em três conceitos fundamentais: destemporalização, destotalização e desreferencialização (ou desnaturalização). Contudo, uma pergunta central permanecera sem resposta. Como o nosso campo - a teoria literária, a teoria da comunicação - ou como as ciências humanas em geral poderiam reagir diante desta mudança de meio-ambiente cultural. Àquela época não sabia quais conceitos substituiriam a teoria literária tradicional, quais os conceitos adequados à modificação da ambiência cultural. $\mathrm{Na}$ conferência de hoje, mantendo a tradição de linhas vindas ao Rio de Janeiro, tenho o propósito de oferecer uma resposta à seguinte pergunta: quais os conceitos teóricos próprios ao ambiente cultural posterior ao colapso da modernidade?

Minha conferência estará composta por quatro partes. Começarei recapitulando, em linhas breves, os três conceitos característicos da situação pós-moderna. Este foi o ponto de partida do seminário de 1988 e sua definição permanecerá como o pressuposto com o qual trabalharei. Na segunda parte, descreverei o que se poderia chamar "o campo hermenêutico", isto é, uma forma de práxis que, em nossas disciplinas, está entrando em crise. Na terceira parte, esboçarei o campo não hermenêutico; este será o momento central da conferência. Por fim, apresentarei alguns conceitos básicos para este campo. Um último esclarecimento: o subtítulo da conferência menciona a materialidade dos meios de comunicação. Entretanto, deles não tratarei concretamente. Acredito que a inclusão da materialidade dos meios de comunicação em nossas teorias exige a invenção de um quadro teórico totalmente distinto. Sem este trabalho prévio, repetiremos o estado atual dos estudos sobre cinema, quando a análise dos filmes, em lugar de enfocar os meios, termina por assemelhar-se à dos textos. Partindo do meu interesse precisamente pela diferença, creio no desenvolvimento de uma teoria radicalmente nova como pré-condição à abordagem eficaz da materialidade dos meios.

1

Começo com a descrição dos três conceitos característicos da situação pós-moderna. 0 primeiro conceito (destemporalização) tematiza o colapso do que podemos denominar "a temporalidade moderna". Temporalidade dominante desde os séculos xV/ xVI, até muito recentemente. Neste paradigma, o tempo confunde-se com a matéria 
que flui de um passado, sempre distinto do presente, a um futuro, entendido como aberto e para o qual seleções podem ser feitas. Em outras palavras, o futuro como preparável a partir do presente. Deste modo, a clássica assimetria entre passado, presente e futuro se constituía. A situação contemporânea evoca um futuro bloqueado. Ao invés da percepção moderna de um futuro aberto a opções, o sentimos ameaçador. Não mais um futuro formado desde o presente, senão um presente ao qual estamos condenados. Ao mesmo tempo, as possibilidades técnicas de reprodução de ambientes e condições do passado se aperfeiçoaram a tal ponto que, constantemente, o presente parece invadido por passados artificiais. Deste modo, as condições de destemporalização insinuam não um tempo que corre, mas um presente tornado cada vez mais extenso.

O conceito de destotalizaçâa, e aqui incluo o Lyotard de La condition post-moderne, explicita a atual impossibilidade de sustentar afirmações filosóficas ou conceituais de caráter universal. Todos conhecem a polêmica de Lyotard contra les grands récits. Já não podemos construir mitologias, filosofias que pretendam abranger toda a humanidade. Neste sentido, por exemplo, a crítica a conceitos como "razão humana" ou "natureza humana". No mesmo contexto, o conceito proposto por Foucault: heterotopologia. Em suma, por destotalização se descreve um esteticismo incipiente no que diz respeito às grandes abstrações.

$\mathbf{O}$ terceiro conceito (desreferencialização ou desnaturalização) trata da experiência do trabalho humano. Trabalho cada vez menos definido como uma apropriação da natureza realizada com o corpo humano. Em outras palavras, em nossa práxis cotidiana, perdemos cada vez mais o contato direto, a fricção do corpo humano com o que se costumava denominar "natureza", matéria. Tal perda acarreta a sensação de enfraquecimento do contato com o mundo externo. Não me refiro ao que constituiria este mundo, mas à impressão de que nos movemos num espaço pleno de representações que já não contam com a referência segura de um mundo externo. Portanto, o resultado destes três conceitos remete ao sentimento de um mundo sempre menos estruturado e sempre mais viscoso e flutuante. Dizendo de outro modo, o sentimento de um mundo não mais fundado na figura central do sujeito.

2

Tentarei agora descrever o que se costumava denominar "campo hermenêutico" Não quero mencioná-lo como uma teoria filosófica ou uma posição acadêmica 
particular. Ao contrário, quando digo "campo hermenêutico" em lugar de "hermenêutica", sublinho que, desde a institucionalização da imprensa no século $\mathrm{xV}$, até duas ou três décadas, o entendimento do que constituía a comunicação, no interior da cultura ocidental, baseava-se em determinados pressupostos não tematizados. Deste modo, o que academicamente chamamos "hermenêutica" não passa de uma versão, por assim dizer, mais sofisticada das premissas básicas. Reafirmando: a hermenêutica acadêmica é uma invenção do final do século xIX, cujos pressupostos contudo remetem ao século xv. As premissas do campo hermenêutico são muito simples, pode-se sintetizá-las em quatro fundamentais.

Primeira premissa: o que denominamos "sentido" tem sua origem no sujeito, em lugar de indicar qualidade inerente aos objetos. Ao sujeito cabe a tarefa de atribuir sentido aos objetos.

Segunda premissa: a possibilidade de distinção radical entre o corpo e o espírito. Pensem na tradição cartesiana e em seu corolário. No caso, o destaque do espírito como o que de fato importa à comunicação e à autorreferência humanas. Ninguém sabe exatamente o que se desejava designar por espírito, contudo tal distinção era efetiva. A terceira premissa é óbvia: o espírito conduz o sentido.

Quarta premissa: neste contexto, o corpo serve apenas de instrumento, ainda assim instrumento secundário, que articula ou oculta o sentido. Por exemplo, a palavra hipocrisia, tornada popular somente no século $\mathrm{xv}$, expressa a técnica que possibilita esconder com o corpo o que vai na alma, quer dizer, no espírito. Importa destacar o papel destinado ao corpo: mero instrumento de articulação, cabendo ao espírito engendrar o sentido.

Estas quatro premissas originaram uma topologia básica, característica do campo hermenêutico. Topologia que explica a relação de correspondência entre expressão e interpretação. Num texto hermenêutico, ao mencionarmos a expressão remetemos à premissa segundo a qual o sentido se engendra na profundidade da alma, podendo ser expresso em uma superfície - a superfície do corpo humano ou a do texto. No entanto, e eis a importância do campo hermenêutico, a expressão, porque limitada à superfície, permanece sempre insuficiente quando comparada ao que se encontra na profundidade da alma. Deste modo, não apenas o corpo é um instrumento secundário de articulação, também a expressão se revela insuficiente. Em virtude desta premissa, no interior do paradigma hermenêutico se impõe a necessidade da interpretação. Interpretação: processo que se inicia pelo que vai na alma de quem se expressa. Como resultado, estabelece-se uma identidade entre o que o sujeito desejava expressar e o entendimento do intérprete. O paradigma 
hermenêutico demanda, pois, o par expressão/ interpretação. Interpretação cuja necessidade nascia da insuficiência intrínseca a toda expressão. Estas premissas básicas eram compartilhadas por todos e não apenas pelos especialistas. Desejo agora mencionar duas sistematizações acadêmicas do campo hermenêutico.

A primeira foi a de Wilhelm Dilthey. A ele se atribui a honra (para mim uma pequena honra) de ser o fundador da hermenêutica acadêmica. A segunda coube a Martin Heidegger. Com Heidegger se alcança a apoteose da hermenêutica (não tratarei de Hans-Georg Gadamer, porque na história da hermenêutica sua importância não se iguala à de Dilthey e Heidegger). A importância de Dilthey deriva da criação de uma disciplina acadêmica a partir das premissas indicadas. Foi ele o primeiro sistematizador do que hoje se denomina The Humanities, no mundo anglo-saxão; Les Sciences Humaines, no mundo francófono, e, na Alemanha, o que é ainda mais interessante, Geisteswissenschaften, quer dizer, as Ciências do Espírito. Dilthey tornou explícito o impulso aglutinador de tais disciplinas. No caso, o fato de todas estarem fundadas no ato de interpretação. Interpretação em seu sentido hermenêutico, como compensação de uma expressão insuficiente. Dilthey afirmava de modo claro que o conceito de interpretação, embora principie numa superfície material, objetiva alcançar uma dimensão que permita o resgate da plenitude da interioridade espiritual. E, acrescentava, a materialidade de superfície com a qual se iniciara - materialidade que se poderia designar materialidade dos significantes - perde importância. Ele o diz com todas as palavras: nas Ciências do Homem (ou Ciências do Espírito) toda e qualquer condição material é apenas um elemento secundário, tanto no ato de expressão quanto no de interpretação. Desse modo, se a hermenêutica se fundamenta no ato interpretativo como denominador comum, apresenta como segundo pressuposto básico a exclusão de todo material.

Considero Heidegger importante neste contexto porque para ele a interpretação não é apenas o centro das Ciências do Espírito, senão o centro mesmo da existência humana. Sua perspectiva se revela muito mais radical, impossível ir além deste ponto, e por isso Heidegger representa a apoteose do domínio da hermenêutica. Como ninguém se permite desconhecer a obra de Heidegger, embora minha experiência demonstre que $99 \%$ não a conhece, destacarei três aspectos do projeto filosófico de Sein und Zeit. Heidegger tenciona realizar uma análise da existência humana. Sua pergunta central: o que é a existência humana? Três premissas devem destacar-se. Primeira premissa: trata-se de uma filosofização da existência humana em geral. Esforço que desconsidera qualquer intento historicista, apesar de empreendido na 
Europa das duas décadas iniciais do século. Premissa anunciada com clareza na Introdução de Sein und Zeit. Ele acrescenta que para se falar da existência humana deve-se captá-la filosoficamente em sua totalidade. O exame atento do texto revela esta obsessão. Ao princípio de cada capítulo, Heidegger adverte da necessidade de partir da apresentação da totalidade do fenômeno. Deve-se sublinhar que uma das bases de Sein und Zeit repousa na premissa da totalidade. Heidegger a pressupõe; entretanto, acredito que já não possamos fazê-lo.

A segunda premissa (mencionarei somente as que importam ao tema desta conferência) considera a existência humana autêntica, diversa portanto da que está perdida no mundo, como fundada entre a consciência da morte - antecipação de um futuro inevitável - e a faticidade - as circunstâncias contingentes e inexoráveis de cada vida individual. Esta segunda condição em parte explica a atitude heideggeriana em 1933. No entanto, para meu interesse destaco a seguinte consequência: se a existência humana autêntica sempre está localizada entre a antecipação da morte como futuro que não se pode evitar e a faticidade, resultante de um passado também inevitável, então, para Heidegger, a existência humana se funda numa premissa de temporalidade. Premissa que creio filosoficamente inaceitável na situação atual. A terceira premissa estabelece a existência humana como sempre realizada no interior do que Heidegger designa estar-no-mundo. Com os hífens pretende-se, por um lado, preservar o paradigma sujeito/ objeto, porém, por outro, ressalvar que o sujeito nunca se pode pensar separado do objeto. Ao contrário, sempre está em contato direto com o "seu" mundo. Desse modo, em sua terceira premissa, Heidegger advoga uma referencialidade geral. Em outras palavras, a existência humana sempre se encontra em contato com objetos e, como se recordará, esta constitui a terceira condição das que penso se tornaram atualmente inadmissíveis.

No entanto, se podemos afirmar que o projeto de Sein und Zeit depende das seguintes premissas: a) totalidade, b) temporalidade e c) referencialidade; deduz-se com certa lógica que à interpretação corresponde o ato central da vida humana. Por isto, para Heidegger, da condição humana de estar-no-mundo deriva o estar-na-verdade. Por estar-na-verdade diz-se que a existência humana é necessária e ontologicamente capaz de captar a verdade dos fenômenos. Para tanto, nem mesmo um esforço particular seria exigido; pois, segundo Heidegger, os fenômenos se revelam em sua verdade a partir de um estado de "relaxamento" (gelassenheit). Condição sem dúvida tributária da perspectiva anti-intelectual do filósofo. Afinal, o estado de "relaxamento" nada tem a ver com o trabalho intelectual de buscar a verdade, depurando-a. Ao contrário, permanecer passivo, sem forçar ou apressar 
a verdade, permitindo que os objetos se revelem em seu ser autêntico, representa o meio de encontrá-la.

Desejo sublinhar que a condição central da existência humana, o estar-no-mundo, implica, para todos aqueles capazes de relaxamento, a possibilidade de estar-na-verdade. Portanto, o estar-na-verdade, isto é, o deixar sair a verdade das coisas, equivale de modo geral e natural à condição humana. Após a primeira edição de Sein und Zeit, publicou-se um breve capítulo sobre a centralidade da hermenêutica. Espero que se tenha compreendido o rumo de minha argumentação. No caso, demonstrar o porquê das premissas fundamentais do projeto heideggeriano não mais se sustentarem. Neste sentido, tornou-se sem dúvida inviável a centralidade do ato interpretativo. Em consequência, comprometeu-se o primado da hermenêutica. Com esta observação encerro a segunda parte da conferência.

3

Duas observações antes de passar ao campo não hermenêutico.

A hermenêutica heideggeriana possui uma particularidade. Todo texto de Heidegger principia pela resposta central. Ao longo do livro desenvolve-se a pergunta, assim como se explica a razão da resposta. Sein und Zeit começa com a resposta central apresentada como intuição, ainda sem base argumentativa; então se articula a pergunta e, por fim, a argumentação é deduzida. Para Heidegger tal método respondia a uma necessidade, pois não se poderia sequer começar a falar de um fenômeno sem a prévia captura de sua totalidade.

Um comentário final sobre o filósofo. Acredito que todo alemão tem a obrigação moral de ser muito crítico com sua obra. Aproveito para esclarecer o que já se terá entendido: não sou nem um pouco tributário a Heidegger. No entanto, é importante reconhecer sua incrível complexidade, ao mesmo tempo em que a resistência a uma teoria complexa pode engendrar nova complexidade.

Tratando agora do campo não hermenêutico, parto de um princípio dedutivo: se, como apresentei, a centralidade da interpretação, não apenas em Dilthey e Heidegger, senão na própria vida cotidiana, estava fundada nas premissas de temporalidade, totalidade e referencialidade e se, hoje em dia, estes conceitos entraram em crise, então se pode supor que a crise atinge de fato a centralidade da interpretação.

Os anos 1970 e 1980 permitem observar sintomas que, retrospectivamente, sinalizam a problematização da centralidade do ato interpretativo. Por exemplo, desde os anos 
de 1960-1970, a crítica ao postulado de uma possível interpretação correta ou adequada. Recordo a Estética da Recepção. Sua meta não privilegiava a interpretação, embora ela fosse de fato interpretativa. Contudo, num primeiro momento, podia-se entendê-la como problematizadora do postulado de uma interpretação correta. Impressão que logo se perdeu. Um segundo sintoma emerge a partir dos anos 1980. Desde então vozes críticas, entre as quais a de Wolfgang Iser, têm questionado o ato interpretativo enquanto ato definidor da crítica literária. Iser, em lugar de recusá-lo, posição com a qual afino, problematiza a premissa natural ou naturalizada de entender $o$ ato interpretativo como o núcleo da competência profissional. Tal crítica teve lugar no contexto do debate sobre critérios de qualificação acadêmica, vale dizer, perguntava-se se os exames a que os estudantes eram submetidos permaneceriam eternamente interpretações. Mais próximo a nós, desenvolveu-se um questionamento filosófico bastante radical do problema da compreensão adequada. Pensem em todas as teorias que adotam a forma o Outro. Nos Estados Unidos, quando se escreve the Other, há o interesse em sublinhar a irredutibilidade das culturas estrangeiras ao ponto de vista que a descreve. Ao fazê-lo, subjaz a premissa da impossibilidade de compreendê-las perfeitamente. Por fim, e tal aspecto importa para esta conferência, não apenas na ação desconstrutivista se encontra tal posicionamento. Num campo teórico totalmente distinto, a teoria dos sistemas, desenvolvem-se reflexões próximas. Por exemplo, os sistemas autopoiéticos partem do pressuposto segundo o qual os sistemas são "cegos" em relação ao que lhes é exterior. E a percepção de um mundo exterior nada seria senão um produto secundário ( $a$ by-product) da autorreferência produzida. Em outras palavras, cada sistema produz uma descrição interior de si mesmo, estabelecendo assim uma referência interna. Simultaneamente, necessita pressupor o exterior, mas o faz sem poder considerá-lo. Não pretendo discutir o mérito destas premissas. Desejo destacar que os últimos dez anos conheceram uma crítica crescente à ideia de uma interpretação do mundo. Acredito que este movimento conduziu a psicanálise a sérias dúvidas em relação aos pressupostos freudianos. Afinal, como é sabido, Freud confiava e se empenhou pela possibilidade de uma compreensão plena e adequada. Aí surpreendemos uma das diferenças entre Freud e Lacan. Em Lacan há um questionamento inicial desta premissa.

O campo não hermenêutico caracteriza-se pela convergência no que diz respeito à problematização do ato interpretativo. Convergência capaz de associar pontos de vista sem dúvida distintos. O que mais importa no contexto atual é a absoluta ausência de uma teoria hegemônica. Nem Derrida, tampouco Foucault ou a teoria dos sistemas desfrutam qualquer tipo de exclusividade. Como um modo de 
representação do campo nāo hermenêutico, empregarei a teoria semiótica de Louis Trolle Hjelmslev. Contudo, faço-o como estratégia de apresentação, pois, para mim, Hjelmslev também pertence ao campo hermenêutico. Emprego sua teoria somente para elaborar uma cartografia. A oposição conceitual básica em Hjelmslev relaciona expressão $x$ conteúdo. Em sentido amplo, expressão seria o significante $\mathrm{e}$ conteúdo, o significado. $O$ interessante em sua abordagem reside no acréscimo de uma segunda divisão. A segunda divisão opõe: forma da expressão e substância da expressão; forma do conteúdo e substância do conteúdo. Reunindo a forma da expressão à forma do conteúdo teríamos o tradicional modelo do signo saussureano. A característica maior do que denomino "campo não hermenêutico" concentra a tendência de distensão e afastamento entre estes quatro campos. A Hjelmslev preocupa a síntese destes quatro momentos. Síntese produtora do conceito de signo, ou significação em vocabulário saussureano. O que me interessa, ao contrário, diz respeito à contemporânea e crescente tendência de distanciar e distender estes quatro campos. Descreverei a seguir este processo. A novidade residirá menos nos objetos aos quais me referirei e mais em relacioná-los aos quatro campos enquanto espaços isolados. Em outras palavras, a possibilidade de tematizar o significante sem necessariamente associá-lo ao significado.

De início observo que o campo da substância do conteúdo apenas foi descoberto pela filosofia e crítica literária. A substância do conteúdo seria uma esfera anterior à estruturação do conteúdo. Não dispomos de conceitos para descrevê-la, pois se trata de uma esfera onde não há binarismos, onde ainda não temos formas do conteúdo. Portanto, esfera anterior ao que se denomina "sentido". Desse modo, a fascinação recente com o imaginário como uma zona prévia à estruturação revela o interesse pela substância do conteúdo. Alguns sintomas: o interesse renovado nos Estados Unidos pelas teorias de George Herbert Mead, que desenvolveu um pensamento específico sobre o imaginário; o último livro de Wolfgang Iser tematizando o imaginário; por fim, o que, estando no Rio de Janeiro, parecerá um tanto tautológico, minha forma de ler a trilogia do Controle do imaginário.

No entanto, importa anotar que, ao mesmo tempo, surgiram teorias preocupadas exclusivamente com a forma do conteúdo. Interesse concentrado nas formas, ou seja, nas estruturas articuladoras da substância de conteúdo, independente de qualquer interpretação semântica. Diria que o Foucault de Les mots et les choses está em verdade voltado às formas do conteúdo, como toda filosofia em torno desta práxis reafirma a centralidade da análise formal. Por formal se entende a estrutura dos discursos que torna possível a articulação das classes do conteúdo. De fato, 
Foucault não está interessado pela substância do conteúdo. A célebre expressão de Foucault, l'extériorité du discours, sinaliza a análise das formas do conteúdo que prescinde da substância do conteúdo. Tendência ainda mais clara em Paul de Man. Sua análise é a das formas que permitem articular o conteúdo, sem que contemple a perspectiva do conteúdo. Por isto, Paul de Man denomina "teoria" uma leitura capaz de prescindir radicalmente do conteúdo.

Cada vez mais temos teorias concentradas em um destes quatro campos. No entanto, embora as teorias se apresentem sempre mais centradas, os campos restantes não são julgados pouco importantes, apenas periféricos em relação a cada pesquisa particular. Neste sentido, parece-me existencialista em excesso a crítica segundo a qual Paul de Man negava a presença do conteúdo, isto é, da semântica. De fato, Paul de Man apenas privilegiou um dos quatro campos referidos. (Com um comentário diria que em Paul de Man não me agrada certa reminiscência do new criticism, em suas análises fortemente centradas nas formas textuais.) Contudo, como sintoma da tendência intelectual contemporânea de concentração na forma do conteúdo, tanto a obra quanto o êxito de Paul de Man são muito importantes.

O terceiro campo do mapa não hermenêutico revela uma fascinação crescente com as formas da expressão. Quando menciono expressão, no sentido de Hjelmslev, estou remetendo às formas materiais da expressão. Em palavras precisas: significantes em sua materialidade. A obra teórica do medievalista Paul Zumthor, por exemplo, tem-se fixado nos últimos anos cada vez mais na voz. Voz, mas não no sentido metafórico e relacionado ao discurso, como empregado por Bakhtin. Zumthor, pelo contrário, está interessado na qualidade físico-sensual da voz humana. Em idêntico contexto, verifica-se a atração de Zumthor e outros pela possibilidade expressiva do corpo humano enquanto meio de articulação. Entretanto, o que é muito importante, sem considerar o lado semântico. Daí o fascínio atual por estudos antropológicos dedicados ao modo de expressão. Por fim, a primeira Desconstrução estava sem dúvida fascinada pela qualidade gráfica de la lettre; interesse que não deve ser compreendido metaforicamente. Acredito que aí se encontra a atualidade do Mallarmé de Un coup de dés para a primeira Desconstrução. Em Mallarmé se surpreendia uma perspectiva fixada na disposição gráfica como forma de expressão. Acrescente-se: forma material da expressão, sem recorrência à semântica. No contexto da materialidade dos meios de comunicação, menciono Friedrich Kittler, um teórico alemão muito interessante. Kittler escreveu um livro, traduzido para o inglês como Discourse Networks, 180o-1900, dedicado à materialidade dos meios de comunicação, incluindo toda a tecnologia de ponta. Kittler especula, por exemplo,

398 - GUMBRECHT, Hans Ulrich. O campo não hermenêutico ou a materialidade 
que o pensamento de Nietzsche poderia ter sido influenciado pela forma da máquina de escrever com a qual trabalhava, isto é, influenciado pelo movimento corporal imposto pelo formato arredondado da máquina de escrever. Importa destacar a conexão, quer dizer, a acoplagem ocorrida entre: a) a materialidade de um meio de comunicação, b) a materialidade de um movimento corporal imposto pelo meio e c) o que tradicionalmente denominaríamos "produções intelectuais".

Para finalizar a descrição do campo não hermenêutico, preciso tratar da substância da expressão. Vimos que as formas dos meios de comunicação, as formas de nossos grafemas e a articulação da voz revelam um novo cuidado pela forma da expressão. Neste contexto, qual a característica da substância da expressão? Por substância da expressão deve-se entender uma materialidade ainda não estruturada. Acredito que daí se origina a popularidade atual do binarismo associado à teoria da informação. Trata-se de saber como é possível a emergência de um sistema de escrita, considerando-se a altíssima improbabilidade de sua articulação a partir dos milhões e milhões de alternativas engendráveis pela fricção de uma pedra sobre outra. Em campo distinto, pergunta similar é enunciada: como, a partir da ilimitada diversidade potencial das possibilidades físicas da voz humana, se produziu um código articulado das formas da expressão? As teorias recentes sobre a pré-história e o aparecimento dos sistemas de escrita constituem o sintoma da atenção crescente despertada pelo campo da substância da expressão.

Termino a terceira parte desta conferência procedendo a um balanço geral da distensão verificada entre os quatro campos. Partindo do pressuposto segundo o qual esta distensão de fato está em curso, a consequência mais importante remete à mudança da técnica central da teoria literária. No ambiente hermenêutico, a pergunta básica inquiria as condições de resgate de um sentido cuja existência se tomava por inconteste. Em outras palavras, o questionamento radicalizou-se: não mais procuramos identificar o sentido, para logo resgatá-lo, porém, indagamos as condições de possibilidade de emergência das estruturas de sentido. Essa preocupação se afasta da situação moderna, testemunhando ao invés a condição pós-moderna.

4

Nos parágrafos anteriores caracterizei o campo não hermenêutico. Gostaria agora de apresentar alguns conceitos próprios a este campo, portanto, independentes do tradicional campo hermenêutico. Deste modo, principio uma resposta à pergunta 
que inquiria da reestruturação do trabalho teórico sob as condições pós-modernas. No entanto, uma resposta incompleta, pois se trata de um work in progress.

A primeira pergunta teórica radicalmente nova constitui a seguinte indagação filosófica: o que é uma forma? Afinal, se, de fato, a distensão entre os campos está em curso e se, em verdade, as novas perguntas investigam as condições da possibilidade de sentido, então precisamos enfrentar duplo problema: a passagem da substância do conteúdo à forma do conteúdo e a passagem da substância da expressão à forma da expressão. Como é possível que algo não estruturado adote uma forma? Deste modo, acredito que a apresentação inicial deve cuidar de definir o conceito de forma. Uma hipótese imediata "profetizaria" a importância crescente que o problema filosófico da forma assumirá nos próximos anos. Pertence a um filósofo alemão a definição mais interessante que conheço. Segundo Niklas Luhmann, uma forma é "a unidade da diferença entre referência externa e interna". Com esta definição, Luhmann assinala que todo objeto, todo sistema a que atribuímos uma forma como qualidade, deve ter, a um só tempo, uma referência interna e outra externa, pois, sem esta, aquela seria impossível. Afinal, sempre que considero um $\mathrm{Eu}$ enquanto sistema, necessito considerar outros que não o sejam. Portanto, o que em termos tradicionais esboçaríamos como uma linha que circunscreve um objeto ou um sistema seria precisamente a forma. A parte circunscrita pela linha, a referência interna; a parte restante, a referência externa. A linha que circunscreve o sistema é o único ponto geométrico que representa a unidade entre as duas referências, pois não há como distinguir em seu contorno a parte pertencente à referência interna da parte que lhe é exterior. Esta definição possui ainda o mérito de recolocar o problema da forma desde um ponto de vista filosófico.

O segundo conceito que se destaca neste contexto é o de acoplagem, oriundo da teoria biológica dos sistemas. Maturana e Varela, dois teóricos sistêmicos, propuseram-no. A valorização do conceito de acoplagem relaciona-se à pergunta sobre as condições de passagem da substância do conteúdo à forma do conteúdo e da passagem da substância da expressão à forma da expressão. Explicando tal passagem, poderíamos entender como forma do conteúdo e forma da expressão se associam, engendrando o que denominamos "representação". Necessitamos desenvolver uma teoria capaz de explicá-la. Para tanto, o conceito de acoplagem poderia permitir o entendimento deste processo. A teoria da acoplagem envolve dois níveis: uma acoplagem de primeiro nível e outra de segundo nível. Por outro lado, o conceito de acoplagem supõe sempre a presença de dois sistemas. 
A acoplagem de primeiro nível explicaria como de substâncias surgem formas, isto é, como substâncias se articulam em formas. $O$ processo da acoplagem seria o seguinte: dada a existência de dois sistemas, Sistema I $\left(S_{1}\right)$ e Sistema $2\left(S_{2}\right)$; se, no $S_{1}$, verifica-se um Estado $1\left(E_{1}\right)$, este $E_{1}$ condiciona no $S_{2}$ um Estado $E_{1}{ }^{\circ}\left(E_{1}{ }^{\prime}\right)$. Por sua vez, se o $S_{2}$ se encontra na situação do $E 1^{\prime}$, então este $E_{1}$ condiciona o $S_{1}$ no Estado 2 ( $\left.E_{2}\right)$. Agora, se o $S_{1}$ adota o $E_{2}$, este passa a condicionar o $S_{2}$ a um $E s$ tado 2' (E2'). Uma acoplagem de primeiro nível entre dois sistemas corresponde ao que na vida cotidiana designamos ritmo. Por exemplo, o samba. Uma máquina apresenta ritmo. Ou o contato do corpo humano com um programa de computador. Importa ainda destacar que uma acoplagem de primeiro nível não é nunca produtiva, quer dizer, o número de estados reciprocamente condicionáveis pode ser muito, porém jamais infinito. Em outras palavras, no interior de uma acoplagem de primeiro nível os sistemas envolvidos necessariamente voltarão a passar pela mesma sequência de estados. Aliás, o ritmo nada é senão a acoplagem de dois sistemas que se condicionam e conhecem idêntica sequência de estados. Em palavras precisas, embora uma acoplagem de primeiro nível possa prosseguir indefinidamente, ela sempre opera retornando a um número limitado de estados. $\mathrm{E}$ este limite nunca é superado por nenhuma forma/ estado novos. Aqui se encontra a especificidade de uma acoplagem de segundo nível, pois, neste caso, a própria acoplagem origina estados novos.

Destaco a importância do ritmo porque acredito que ele constitui precisamente o que designamos por forma. Pois, uma vez que o obtemos, dispomos de uma estrutura de autorreferência que ao mesmo tempo produz uma referência externa. Portanto, se uma acoplagem de primeiro nível produz um ritmo, então talvez represente um teorema capaz de explicar a passagem das substâncias da expressão e do conteúdo às formas da expressão e do conteúdo.

A acoplagem de segundo nível diferencia-se da de primeiro por seu caráter produtor. Nela, a própria acoplagem engendra estados novos, previamente desconhecidos. Em uma acoplagem de segundo nível o número de estados pelos quais passam os sistemas é infinito. Por exemplo, a linguagem humana. Do modo como a concebemos, constitui uma acoplagem de segundo nível, uma vez que cada um de nós produz continuamente enunciações jamais articuladas.

A diferença entre as duas modalidades de acoplagem possui outra consequência importante. No caso, o caráter produtor da acoplagem de segundo nível permite, a certo grau de complexidade, um estado de auto-observação. Este estado seria a condição necessária à possibilidade de representação. Condição do que denominamos 
"semântica", condição do que acreditamos constituir a referência. Isto porque o estado de auto-observação, característico da acoplagem de segundo nível, concentra um caráter paradoxal. Por um lado, sendo parte da acoplagem, dela se origina; por outro, parece independer-se da acoplagem, pois permite observá-la desde seu exterior. De fato, faz parte da acoplagem, no entanto, pretende observá-la como se não o fizesse. E, uma vez que a acoplagem de segundo nível engendra a ilusão, impressão de realidade, isto é, quando emerge o estado de auto-observação, então já se dispõe de um nível de observação ou de representação: um nível semântico. Este teorema por certo está longe de ser completo. Contudo, acredito que, trabalhando o conceito de acoplagem de segundo nível, poderíamos desenvolver uma teorização da pergunta: como de um estado de formação se atinge o de representação?

Tal trabalho teórico implica a valorização da materialidade. Ao descrever a acoplagem do corpo de Nietzsche com sua máquina de escrever, devo considerar que a forma material desta máquina desempenha um papel decisivo na constituição do sentido. A máquina, enquanto forma, contribui à acoplagem. Portanto, acrescentaríamos a possibilidade de incluir $o$ aspecto da materialidade dos meios.

Neste contexto, gostaria de mencionar um terceiro conceito. $\mathrm{O}$ de simultaneidade, conceito que deverá substituir os de temporalidade, causalidade ou sequencialidade. Ora, se o novo espaço teórico representado pelo campo não hermenêutico é constituído por relaçōes de feedback, tais relações definem-se enquanto simultâneas; não mais causais ou sequenciais. Uma consequência interessante derivada do conceito de simultaneidade remete ao "ocaso" do sujeito. Pois agora se pode inteligir o fascínio moderno pela temporalidade, causalidade e sequencialidade. As relações fundadas nestes conceitos fornecem a ilusão do estabelecimento de leis. Leis como as marxistas, estruturadoras de sequências temporais, históricas e comportamentais. E, tão logo o sujeito desfruta desta ilusão, quer dizer, ao intuir ou "certificar-se" da descoberta de tais leis, acredita-se capaz de controlar e/ou manipular suas consequências. Deste modo, a substituição dos conceitos modernos pelo de simultaneidade expōe outro sintoma da posição fortemente debilitada do sujeito. Tal substituição implica a passagem do conceito de necessidade de um desenvolvimento ao de contingência de uma relação simultânea. Toda teoria possui seu ponto cego. Na teoria dos sistemas, a pergunta que permanece sem resposta indaga por que se produz uma acoplagem entre dois sistemas. Por isto a crescente importância do conceito de contingência (randomness) em nosso campo teórico.

A tonalidade teórica atual assimila a importância do conceito de contingência de dois modos. Por um lado, sem dúvida projeta-se uma imagem trágica do mundo, 
uma vez que, sendo as acoplagens contingentes e, ainda por cima, contando com um sujeito enfraquecido, devemos assumir a incapacidade de controlar o que ocorre no curso das acoplagens. Em consequência, vivemos o eclipse da posição do teórico que sempre sabia em que direção caminhava a humanidade. Por outro lado, esta mudança poderia impulsionar uma tarefa política no sentido tradicional, cabendo aos teóricos sublinhar o conceito de contingência. Pois a perda do sujeito para além do fim da ilusão das leis da necessidade histórica e, portanto, do desejo de orientar o futuro - representa uma enorme liberação: se o sujeito não é mais o centro, então ninguém pode falar em nome do sujeito transcendental. Todos os sistemas totalitários, políticos ou de pensamento, pretenderam falar em seu nome. Desse modo, ao menos em termos pessoais, posso dormir muito mais tranquilo na presença desta ausência.

\section{DEBATE}

Luiz Costa Lima - Primeiro, um comentário. Considero fundamental esta sistematização inicial, dividida em duas partes. Uma, referente à hermenêutica. A outra, uma proposta para o novo campo.

Em relação à primeira parte, destaco o relacionamento entre a centralidade do sujeito e o campo hermenêutico. Como uma corroboração acrescentaria: ao tratar da sistematização da ideia de hermenêutica, você sublinhava como em seu interior a materialidade possuía um papel secundário, a ideia fundamental remetia à interioridade ou ao espírito. Recordei, por acaso, de uma pequena passagem de Schopenhauer que me impressionou negativamente, confirmando o ideal hermenêutico. Dizia Schopenhauer que o menos importante num romance se refere à ação. A voz interior, eis o que de fato conta. Curiosamente ele exemplificava com o Quijote, Tristram Shandy e Wilhelm Meister. A ideia do sujeito trazia consigo esta inferioridade material, privilegiando a espiritualidade. No interesse da passagem de Schopenhauer podia-se pensar em uma outra de Diderot, que segue idêntico caminho. Este tipo de reflexão importa ao revelar como o conceito de literatura está preso à desvalorização da materialidade e à ênfase na voz interior do sujeito, no privilégio da ideia de sujeito. Reflexão importante para se chegar a um novo estatuto da noção de literatura.

A segunda observação: considero que o conceito de forma, tal como apresentado por Luhmann, responde àquela significativa demanda, isto é, à pergunta teórica sobre o 
que constitui uma forma. Afinal, ao questionamento da hermenêutica corresponde o da noção de centralidade do sujeito. Então, para não recair numa mera estetização, é necessário perguntar-se pelo que vem antes do sentido, investigando como ocorre esta transformação posterior. Portanto, a ideia de forma como unidade de diferenciação entre referência externa e interna, eu a traduzi de imediato no que denomino "mimese da produção" Por um lado, considero a determinação da forma como condição a partir da qual o sentido emerge, arqueologicamente decisiva para evitar o primado do semântico, primado que determinava a busca de constância expressa em leis. Por outro lado, em relação à ideia de acoplagem vejo um problema que gostaria de destacar. No caso, o compromisso de tal noção com outro conceito básico no interior da modernidade. Diria: os dois conceitos fundamentais trabalhados do século xviII em diante são os de estrutura e função, além da ideia de sujeito. Por exemplo, Diderot, em De l'interprétation de la nature, trabalha de forma muito clara com a ideia de função. E função como equilíbrio, como feedback. O que me parece digno de indagar-se é o quanto as noções de feedback e de acoplagem permanecem dependentes da de função, continuando a privilegiá-la. A consequência destes conceitos básicos pode ser assim caracterizada: a ideia de estrutura permite pensar-se na assimetria, na contradição. Ao contrário, a de função supõe um conjunto que se equilibra, logo autopoiético. Não por acaso ela é fundante à possibilidade do funcionalismo antropológico. $\mathrm{O}$ ponto com o qual não afino refere-se à semelhança entre as noções de acoplagem e função. Lembremos da antropologia clássica. A ideia de funcionalidade exclui o elemento anômalo, o elemento sem função. Ao menos segundo meu entendimento, a acoplagem apresenta este ponto débil.

Hans Ulrich Gumbrecht - Começo por um acréscimo. Luiz dizia que a ideia, reencontrada em Schopenhauer, da interioridade como oposta à materialidade predominava. Creio que no pensamento europeu, sobretudo na segunda metade do século XIX, era uma obsessão quase onipresente. Obsessão sem dúvida anterior a Dilthey. Ele nada fez senão utilizá-la para fundar uma instrução acadêmica. Sua inovação consistiu em sistematizar uma ideia pregnante no século XVIII, tornada sempre mais obsessiva na segunda metade do século seguinte. Portanto, a inovação de Dilthey se concretiza na institucionalização do dualismo acadêmico. Em outras palavras, o conceito das Humanidades funda-se no pressuposto segundo o qual qualquer tema pode ser discutido, exceto o corpo humano: o único objeto excluído sem remissão. Mencioná-lo em seminário para estudantes no College provoca invariavelmente a pergunta: este assunto não diz respeito à Faculdade de Medicina? Eis 
a importância de Dilthey. Gostaria de citar Nietzsche para situar uma posição contemporânea à de Dilthey e Schopenhauer, porém oposta. Faço-o como acréscimo ao que Luiz recordava. Numa passagem da Genealogia da moral, Nietzsche trata de Flaubert, esclarecendo como se desenvolveu seu gosto pelo escritor. De imediato, pensa-se no gosto enquanto gôut, isto é, apreciação estética. No entanto, Nietzsche aclara que seu gosto nada possui de espiritual, pois em verdade desejaria "mastigar Madame Bovary"

L.C.L. - Um acréscimo ao acréscimo. Mastigar, comer, alteridade, sociedade diversa; em suma, dentro da tradição europeia esta diversidade foi domesticada através do exotismo. Não por acaso, em geral para o europeu ou o americano a imagem dos trópicos se sintetiza na frase: "Pelé e samba!" Ou a frase, ou uma gesticulação qualquer, ou seja, aí o corpo aparece. $O$ corpo é este lugar, um outro campo, agora exótico.

H.U.G. - Complementaria dizendo que Proust - pensemos no conceito de gôut relacionado ao famoso episódio da madeleine - transforma o conceito de gosto em um conceito corporal. $O$ interessante episódio da madeleine reside na definição do gosto enquanto uma relação psicofísica. De certo modo, e sem com isso afirmar que Proust fosse nietzscheano, a mesma ideia da insuficiência da pura espiritualidade já se encontrava no filósofo. Também a encontramos no episódio central do romance proustiano, na própria constituição de um passado.

Agora, a segunda ideia: a associação entre forma e mimese me parece fantástica. Queria esclarecer o emprego que faço do conceito de forma. Ao considerar que o conceito de forma adquirirá cada vez mais importância nas futuras discussões teóricas, não digo que necessariamente retornaremos à tradição "formalista" da forma. Diria intuitivamente que o conceito exigirá uma nova pergunta. No caso, como algo não estruturado, o denominado "subconsciente", pode passar a algo articulável? Creio que a pergunta de fato significativa indagará da emergência de algo que mais ou menos articula a substância do conteúdo, sem retorno ao conceito tradicional de forma. Esta passagem está precisamente baseada em um conceito de diferença. A pergunta que importa refere-se às condições de possibilidade da passagem de algo não articulável a algo articulável.

Karlheinz Barck - Concordo que o importante é desenvolver um pensamento crítico frente aos conceitos que nos foram transmitidos, incluindo o que você bem descreveu como o campo hermenêutico. Trata-se de uma tradição fundamental e 
que, a princípio restrita à Europa, se difundiu por todo o mundo através de certos imperialismos. A primeira tarefa para alcançar o que você denominou um "campo não hermenêutico" seria, a um só tempo, proceder à crítica dos conceitos herdados e elaborar novos conceitos. Por certo, não podemos assumir o papel do iconoclasta, desprezando todo e qualquer conceito. Cuidado evidenciado no conceito de forma, por você repensado, em busca de uma nova configuração. Deve-se criticar a filosofia hermenêutica que ontologiza tanto os conceitos, quanto os problemas da vida. Neste sentido, concordo com a crítica feita à hermenêutica representada por Heidegger.

Benjamin preocupava-se muito com o problema da forma, objetivando diferenciá-la do conteúdo, como se pode verificar em seu ensaio "A tarefa do tradutor" No entanto, Benjamim trabalha com conceitos dinâmicos, "conceitos de projeção", como os tenho denominado. Ao fazê-lo, questiona a ontologização dos conceitos.

Para tanto, não fala em forma, mas em formação; em lugar de reprodução, emprega reprodutibilidade; não diz tradução, senão traduzibilidade. Nestes conceitos, vislumbro a linha que você apresentou.

Desta ordem de preocupações, minha primeira pergunta. Sua conferência desenvolve o problema fundamental do tempo. Quando você afirmou, em sua exposição introdutória e ao mencionar a filosofia heideggeriana, que o pensamento pós-moderno se caracteriza pela presença de uma destemporalização, pergunto: o que se diz com tal afirmação? Não sinalizaria a necessidade de buscarmos outro conceito de tempo? Tempo participante de tempos diversos, em todos os níveis - cultural, histórico, psicológico etc. -, em lugar de um tempo único, eurocêntrico. Aí encontro uma relação com o conceito de forma. Então pergunto: onde situar o campo da estética no interior desta reflexão? Esclareço: campo estético não no sentido substancialista hegeliano, mas na acepção benjaminiana de um retorno e um avanço ao conceito originário de Aristóteles. No caso, partindo da percepção, dos modos da percepção e da perceptibilidade, como diria Benjamin. Qual poderia ser o contato entre forma e tempo capaz de movimentar estes conceitos? Talvez, para realizá-lo, elaboraríamos um campo específico no interior do campo não hermenêutico, compondo um segundo campo. Como exemplo de modos de pensar ou de construir específicos, recordaria o pensamento alegórico. Pensamento que é um pôr em forma através de um modo dialetizador do tempo. Afinal, como Paul de Man demonstrou, tal pensamento se caracteriza precisamente por uma dimensão temporal fundamental à sua produção. Nesse sentido, um dos impasses no campo hermenêutico heideggeriano (fruto de sua arrogância anti-intelectual coerente com a lógica de sua filosofia) não decorreria da recusa da pluralidade dos tempos? 
Acrescento uma segunda observação, pois desejo saber o que você pensa a respeito. Não estou de acordo que o "caso Heidegger" constitua responsabilidade particular dos alemães, cabendo portanto a eles o desenvolvimento especial de uma crítica ao filósofo. Acreditar nisso seria incorrer, sem dúvida inconscientemente, numa conotação nacional de problemas teóricos. $\mathrm{O}$ "problema Heiddegger" é um problema universal. Neste contexto, importa muito o enfoque de uma crítica política ao pensamento heideggeriano, desenvolvida pelo grupo filosófico de Estrasburgo. Por exemplo, vejam-se os livros de Philippe Lacoue-Labarthe, La fiction $d u$ politique (1987), e de Jean-Luc Nancy, La communauté désoeuvrée (1990), ambos publicados por Christian Bourgois Editeur.

H.U.G. - Principio pela observação final. Em verdade, meu argumento sobre Heidegger não era sério demais. Nesse sentido, estou totalmente de acordo que a tarefa de criticar Heidegger não pertence a esta ou àquela nacionalidade. Era uma frase retórica, pois o fato de ser alemão ou falar com sotaque germânico parece associar quem menciona o filósofo a determinada atitude política.

Como sua recapitulação da conferência explicita, estamos às voltas com o declínio de um paradigma. Em relação à primeira pergunta, estou totalmente de acordo que o interesse maior se encontra na distinção benjaminiana de conceitos emergétiços ou conceitos de projeção. Na segunda parte da conferência, todos os conceitos centrais eram conceitos compostos que continham, como primeiro elemento, a ideia de emergência. Creio que este aspecto corresponde exatamente ao que você destacava no pensamento benjaminiano.

Enfrento agora as duas perguntas mais difíceis.

A primeira relaciona-se ao problema do tempo. Quando falo de destemporalização, refiro-me de fato ao colapso do tempo histórico.

Tempo histórico: construção do tempo caracterizada por: a) uma assimetria constitutiva entre passado, presente e futuro e b) a premissa segundo a qual o tempo era necessariamente um fator de mudança, isto é, a passagem do tempo implicaria correspondente modificação nos fenômenos. Esta correlação pode ser produtivamente contestada por uma concepção filosófica diversa do tempo. A pergunta resultante: pode-se dissolver a conexão, apresentada como necessária, entre o fluxo do tempo e a inevitabilidade de mudança nos fenômenos no tempo? Em outras palavras, a pergunta persegue um conceito de tempo que permita o fluxo temporal indispensável à relação de feedback, sem que por força se produzam mudanças neste intervalo de tempo. Creio que um sintoma deste interesse se revela na preocupação/ 
fascinação filosófica recente pela repetição. A repetição como a possibilidade de desenvolver-se um conceito de tempo cujo fluxo deixa de constituir fator inexorável de mudança. Lacan o tentou. Acredito que o emprego por parte de Benjamin do tempo messiânico pertence à mesma sintomatologia. Afinal, o tempo messiânico ao menos permite exceções à regra segundo a qual o tempo é fator necessário de mudança. Quando falo em destemporalização, pretendo, em lugar de eliminar o conceito de tempo, substituir o conceito de tempo histórico, conceito que por quatro séculos foi aceito como único. Assim, é provável que o conceito de tempo possa entrar numa heterotopologia, pois, para distintos contextos conceituais, teríamos conceitos diversos de tempo.

A outra pergunta difícil relaciona-se à estética. Principiaria a resposta com um reparo crítico. A pergunta pelo lugar da estética em um sistema pressupõe para a estética um estatuto transcendental. Deste modo, minha primeira resposta afirmaria que tal lugar não mais existe: ele tende a desaparecer. Não estou totalmente convencido desse desaparecimento, mas creio que o mesmo se aplica ao conceito de Literatura. Neste sentido, nada torna os críticos literários mais nervosos que a problematização do conceito de literatura ("pois, sem literatura, como preservar a profissão de crítico literário?"). Acredito que precisamos permanecer flexíveis para pensar a possibilidade da dissolução de noções como as de "literatura" e "conceito estético".

Uma possibilidade de responder positivamente a sua pergunta seria definir a estética como um conceito relacional, em lugar de ontologizá-la. Imagino que você concordaria com tal definição. Precisando: o que denominamos "estética" refere-se sempre a uma relacionalidade especial entre algo já institucionalizado e algo ainda-não-institucionalizado. Tal alternativa concentra a única possibilidade de desenvolver um conceito meta-histórico de estética e, aqui, um tanto na acepção de Mukarovsky. Se esta é uma possibilidade para uma definição da estética, então, a partir do esboço do campo não hermenêutico, um lugar possível da estética estaria fundado na dissolução do pensamento cuja premissa supõe um sentido desde sempre presente. Assim, por exemplo, qualquer produto que permita dissolver um sentido que já se encontre articulado ao que denominei "substância do conteúdo". Em outras palavras, qualquer articulação ou produto que autorize a passagem do sentido já articulado - como o resultado de uma acoplagem de segundo nível - a uma acoplagem de primeiro nível. Um exemplo: a forma de leitura proposta por Paul de Man. No caso, ler um texto resistindo à semântica. Nos dias atuais, uma manifestação artística definível como portadora de um efeito estético seria o grupo de

408 - GUMBRECHT, Hans Ulrich. O campo não hermenêutico ou a materialidade 
dança de Pina Bausch. Sua forma de dança apresenta precisamente um ritmo não semantizável, ou seja, desenvolve-se uma coreografia de corpos num movimento rítmico produtivo que recusa toda atribuição de sentido. Agora sua dança se encontra institucionalizada, isto é, independente do que mostre, todos se encantam. No entanto, quando sua dança ainda era uma novidade, provocava reações totalmente histéricas. Tal reação decorria não apenas da ausência de sentido, mas, sobretudo, porque esta forma artística rejeitava com agressividade qualquer doação de sentido. Por fim, estou sem dúvida de acordo com você no que diz respeito a Heidegger. O lugar de uma estética relacional está ausente de sua filosofia, porque nela não se valoriza essa possibilidade. Ao contrário, seu esforço objetiva fortalecer seguranças perdidas. O projeto de Sein und Zeit - deste modo o caracterizo em meus seminários - pretende salvar o paradigma sujeito/objeto em plena consciência da impossibilidade de fazê-lo. Neste contexto, a filosofia de Heidegger é por certo conservadora. No entanto, não somente no sentido político; conservadora porque se trata de preservar um paradigma. O que a torna mais interessante que um puro conservadorismo? Ora, tal esforço de resgate desenvolve-se na plena consciência de sua impossibilidade. $\mathrm{O}$ fato de Heidegger ter sido aluno de Husserl - o primeiro a desmoronar completamente o paradigma sujeito/objeto - é a razão pela qual reconheço o inegável interesse da posição de Heidegger, embora dele não possa estar mais distante. Quase sempre o esforço em realizar algo em plena ciência da impossibilidade engendra uma enorme complexidade intelectual. Esta a razão pela qual acredito que Heidegger deva ser lido.

Hans Ulrich Gumbrecht é professor na Universidade de Stanford, autor de Production of presence: what meaning cannot convey (Stanford University Press, 2004); Modernizaçāo dos sentidos (Editora 34, 1997); Corpo e forma: ensaios para uma crítica não-hermenêutica (Eduerj, 1998); Materialities of communication (Stanford Press, 1994, coautoria de K. Ludwig Pfeiffer); entre outros. 